\title{
Key Lessons from Covid-19: The Worldwide Pandemic
}

\author{
Enlenca Dsouza and Swarupa Chakole \\ Medical Intern, Department of Community Medicine, Jawaharlal Nehru Medical \\ College, Datta Meghe Institute of Medical Sciences, Sawangi (Meghe), Wardha \\ Corresponding author email: dsouzaenlenca@gmail.com
}

\begin{abstract}
Wuhan was the epicentre of COVID-19 pandemic in China from where this dreaded infection reached different countries and startled the healthcare system throughout the world. The infection took a form of storm resulting in collapse of healthcare system and economy throughout the world. Even the top countries with strongest economy and world's best healthcare system were not spared. This dreaded virus had taken a toll of millions of livesand drowned the health care system and economies of almost all developing countries. Thiswas the biggest challenge the world faced. Human is still struggling to cope up with it. But this pandemic proved to be the eye-opener for entire world and humanity. It made the world realise the true value of environmental balance, healthcare personnel and hygiene maintenance. Many debates emerged on the grounds of prevention, control and treatment of COVID and research wheels were thoroughly moved to prepare vaccines for containing pandemic and human losses.
\end{abstract}

KEY WORDS: PANDEMIC, COVID-19, WORLD, HEALTHCARE, ECONOMY, HUMAN VALUES.

\section{INTRODUCTION}

To say life has changed amidst the pandemic is probably an understatement to what we all are facingnow. With the outbreak of COVID 19, our lives have taken a drastic change way beyond recognition. Thousands of people affecting every social sector of the spectrum are in lockdown unable to do what they were doing prior to the pandemic. Everyone's lifehas come to a standstill. Not only life has halted on the work front, but it has affected all aspects of life. We are now confronted with the harsh realities and questioned about the true uncertainty of humanity and if we would ever really overcome this.

Body: With the outbreak of corona, we have been put to question about the basic things in life: What is the sole purpose of our life? What are we currently doing with it? The Covid 19 pandemic has left a deep void in all of

Biosc Biotech Res Comm P-ISSN: 0974-6455 E-ISSN: 2321-4007

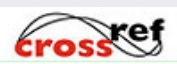

Identifiers and Pagination

Year: 2021 Vol: 14 No (6) Special Issue

Pages: 153-157

This is an open access article under Creative

Commons License Attribn 4.0 Intl (CC-BY).

DOI: $h t t p: / / d x . d o i . o r g / 10.21786 / b b r c / 14.6 .34$

DO1: hittp://dr.doi.org/10.21786/bbre/14.6.34 us and has given us some painful insights: If we know what is important to us and what we truly cherish, then why have we spent so little of our lives pursuing these things?

The pandemic has got us thinking to how much time we have wasted running after things that do not really matter and how much of the important things we have left behind in that process. It tells us how we're fighting endless battles for wealth, status and power and how much we've actually forgotten the value of people: not only family, friends, loved ones but also our behaviour towards completestrangers. It has opened our eyes to the fact that even if you're rich or poor, we are all interdependent on each other in one way or another. Every person has their own unique experience as to how they're tackling the pandemic and what they've learnt or still learning through this.

\section{DISCUSSION}

Firstly, the health care workers, nursesand all the frontline workers should be fully trained as to how to handle emergency situations when they face it. They should have the needful skills and be equipped with basic instruments and be trained under stressful pressurizing conditions

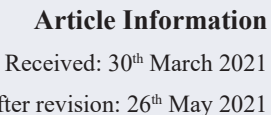

ccepted after revision: $26^{\text {th }}$ May 2021

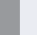


with minimal chaos. They also have the most risk to get exposed and hence the healthcare systems should protect them in proper and stringent ways. Better outreach services should also be provided to people living in far off areas so that they can access the healthcare facilities as well. In all natural calamities, it's the poor, poverty stricken, underprivileged that happens to take the brunt of an effect.Covid 19 is no exception. It has affected the high class as well but not as much as how many poor people have been affected.

The most important factor that we have learnt is that the ratio of healthcare workers to the general population is still very low. (Khoo et al., 2020) This would mean that significant importance should be given to not only respected fields like doctors but nurses, healthcare workers who are the first line of defence against the virus should be given top priority as well. With the pandemic, people have been very dependent on the healthcare sector and proper eligibility criteria should be fulfilled before training them. Emphasison practical knowledge and skills rather than basic theory should be the focus for our upcoming healthcare population so that they're prepared for any future crisis.

The way to create more healthcare opportunities should start at the grassroot level in terms of education where certain information like the understanding of basic hygiene for example: washing of hands or using a handkerchief to sneeze should be introduced at a very early stage of a child's development (by parents and teachers).Instilling qualities by parents and teachers for example : provide a helping hand to one's in need, good communication skills to all people of every class,etc. (Gudi et al., 2020) Children should not have the pressure from parents,peers,teachers to become a doctor or a nurse or a healthcare para-personnel,they should want to take the competitive exams by their own mind and should be encouraged in doing so.Just because parents are doctors shouldn't necessary mean that the kids want to become doctors as well, some kids have been forced into this and hence they turn out to be the ones with the most medico negligence cases and reason of high patient deaths.

From the government's side, more investment into medical colleges would create more opportunities in the government and the private sector which would drive the economy as well. Government should focus on funding of medical colleges in every state so that there's more opportunities for the aspirants. Proper and working tools and machines should be given to these colleges. Medical centres and more research centres should also be setup in the country. (Kaebnick et al., 2020) Insurance schemes should be updated by the government in times like these in both urban and rural population. Government Funding in insurance related schemes and crisis management is extremely crucial for an economy like ours to ensure that the population at large is protected to some extent.

People of all social status should be made aware of the schemes especially with the medical insurance so that a lot of money can be saved during such pandemics
After the outbreak the insurance regulators have been promoting different policies, but this would have been more convenient if people had already been made aware of this beforehand.However a stringent watch should be made on the fact that only the rich shouldn't be benefited from this and poor people exploited. It has made us to realise that sadly, a pandemic has made us realise how significant hygiene is and how it should always be maintained.

COVID or NO COVID, basic sanitation in our daily routine is very important for not only ourselves but also for people around us. It has been seen that there's an upward graph in soap sale marketing only during times of crisis which reflects to the fact that how all of us really maintain hygiene. From a small age itself we all should be taught the true value of keeping ourselves clean so that we all can live in a better, cleaner and safer world. The importance of Hand-Sanitizers (personally or commercially) is also to be noticed. There have been so many instructional videos from the World Health Organization on the correct technique of washing hands to ensure that you do not put yourself at risk along with others. Not only handwashing in these times, wearing a mask has been a new normal. The price rates of sanitizers and face masks has also dropped since the last few months so that people from sectors can be buy them. Wearing a face mask and gloves especially for the medical personnel has also been promoted.

The only problem is that while we are aware of hand sanitizers,masks,PPEs, there are some places in our country that know nothing of this. Proper awareness campaigns regarding the spread of covid and measures used to protect us from contracting the disease should be done amongst these people. (Roman et al., 2020) In the future, there will be more importance given to the following: waste management - focusing particularly on open Garbage spotswhere the risk of exposure is high. Since the wake of COVID, all we hear is "social distancing. So, what is social distancing really? In a more theoretical term, social distancing is basically the need to maintain space between people and to avoid large crowd gatherings. (Miller et al., 2020) The Centres for Disease Control and Prevention (CDC) tells people that a 6 feet distance or about 2 arms' length is required whenever possible.

So how does this really help? It not only keeps a physical distance between people and reduces our contact with people but it actually helps us to flatten the curve that is by being isolated in our homes the rate of further spread reduces and it'll be easier to just eradicate the disease in a time lesser than what it would normally take if social distancing norms were not followed. Since there is no physical contact, there wouldn't be any transmission and it would decrease the possibility of spreading disease to others and hence we would achieve flattening of thecurve. (Sterpetti et al., 2020) This also decreases the burden on the front-line workers and gives them the chance to keep up with the number of people who need treatment. 
Not only this, but due to social distancing and being quarantined and isolated at homes people have given other people space and this has only helped them in their personal relationships. Yoga offers a wholesome amount of benefits to help everyone during this difficult COVID19 pandemic situation. These are some of the advantages that one would experience if Yoga is added as an activity inlife: -yoga helps to loosen tight muscles,adds stability, flexibility and balance in the workout, helpful in the control of aches and pains as tight muscles heal and relax, heart rate climbs as you get better and the physical results would be visible, muscle building, increase your endurance, boost your lung capacity and improve your bone density.

Not only all this but yoga and meditation also gives us a sense of calmness and helps to reduce anxiety and gives life more stability. (Chang et al., 2020) It actually helps us to have a more destressed mind and helps us carry on with our days with more of an open mind. People in isolation who are alone with nowhere to go and confined within the four walls are finding it very difficult to cope up with their mental wellness. However, mental health hasn't been talked about so much as it has been due to corona. This just shows the lack of insight we have towards something that's so important for our personal wellbeing. Everyone should be healthy not just physically but mentally as well. Talking about what they feel really helps and people should know it is okay to express your feelings.

There's been a huge increase in talking to psychiatrists, psychologists and counsellors over the internet in these past few months and people are now getting aware of how important mental health is. People with mental health issues would have experienced high levels of distress during this time. It is important to acknowledge that anxiety, mental stress and depression will be the likely outcome during the lockdown and pandemic. Looking after and prioritising mental wellbeing is very important at times of increased stress. Lessons to be learned are as follows: Exercise, diet, emotional wellbeing and sleep are all important for mental health and wellbeing. These are usually the most important items that are neglected during times of stress. It is important to speak to family, friends and relatives and think of ways to maintain each of these. It important for you to be vocal about such things and encourage such known person to consider the need for assessment especially when someone displays changes to their mental health, such as increased anxiety or sleep disturbance, or other symptoms of relapse. In olden times mental health wasn't even considered as a condition to seek help for, hence the older people should also be made aware about this being a condition that can be treated.

Some people with mental health issues may be more vulnerable to negative messages in the media. (DePierro et al., 2020) Hence we need to ensure that the people know how to access accurate, up to date information and correct misinformation. All of us have just been running in this rat race called life without giving ourselves or family time. The pandemic has not only helped us on slowing down but also helped us diverge focus on our loved ones. Prior to this, people only worked and had no time for the ones at home but now due to the pandemic and being stuck with each other all day, we have strengthened the already strong relationships and mended the broken ones.

Family life has taken a turn for the better for all people and helped us value them in our livesmore, from having family movie nights to playing board games or just discussing issues in general, it has all worked out. For those away from families, videocalls once in three days or a week has given them something to look forward to. Digital media has also been taken for a turn not only in relation to entertainment but also for knowledge. People sort out to using the internet for basically everything but this can be both an added advantage and disadvantage and it depends on how we use the net.Gamers,people addicted to online chatting, people who watch movies all the time, should try to stop the addiction and maybe try out something different. Some people have picked up different skills over the internet like learning a new language, taking a Zumba class online, learning different instruments via the web, from showcasing their cookery skills on social media or to even finding meaning in the little things in life, these are some of the things they'd never have done if they hadn't put the pause button. (Kalfa et al., 2020) This just explains how much this pause was actually required for us to extract our best of capabilities.

People have realised that communication can be maintained not only physically but with the help of technology aswell. Long lost friendships, people away from homes, it's easy to stay in touch now with all the free time. Schools, colleges and offices are now conducting their activities on social media apps like ZOOM or WATSAPP, Microsoft Teams or Skype. WORK FROM HOME is now a new normal. This has not only helped us to be flexible with our work timings but it has also reduced the maintenance charges on setting up a workplace and the taxes behind it. This ensures people to be highly efficient in work since they're allowed to be flexible with their time. Virtual classrooms for example, have been expanding without need for space to accommodate these students. (Khanna et al., 2020) Online tests and discussion have been helpful and access to international online education gives us an upper hand to compete with international students as well.

Temples,churches,mosques and other places of worships all have been using an online portal to recite prayers and this helps to reduce mass gatherings. This has helped us to not only still maintain ourselves in prayer but also reduce the transmission of disease in this process. This has also helped us understand that we don't have to physically be present and hence can save a lot on time and travel and more importantly exposure to risks. Telehealth or Teleconsultation in the healthcare sector is also another growing industry whereby some countries have instructed its residents not to go to hospitals for 
elective treatments for some time and have adopted a Telehealth model where people can video consult or tele consult a doctor available for minor issues. Some countries have the model where the insurance companies can authorize dispense of medication. (Lawrence et al., 2020) Home delivery of medication will also be a growing industry of the future. More measures should be taken as to how the medicines can be delivered in all sectors, high or low.

Elderly, adults with co-morbid conditions and malnourished kids should be taken care of better during times of pandemics. Sincecorona, many deaths are from this high-risk groups only and hence it is of utmost importance to isolate them in times like these in future.(Forman et al., 2020) Proper health surveillance systems and national data collection that's to be updated on a regular basis should be made to pre-identify these vulnerable groups during a disaster. There has been a decrease in deaths related to road traffic accidents since the lockdown. Ambulances for emergencies could actually take patient to hospital before their deaths showing that traffic has always been a major issue. Human beings have been living beyond the planet's boundaries. Nature activists have been screaming about this for a while now, but we've been ignoring them. Return of colour of natural skies, fresh air without much pollution from automobiles and industries, cleaner waters in rivers and seas without the garbage being thrown in them, shows us that how we've been badly messing up nature all these years. It took a global shutdown for our planet to rejuvenate herself and henceforth proper regulations should be followed for this to be maintained even post pandemic. (Khan et al., 2020)Stricter rules should be made related to nature being manhandled and should be put into action effective immediately.

Research centres should be on the forefront and up and working. Drug and vaccination programmes should be developed further for better management. Manufacturing of proper equipment for a pandemic is required. COVID 19 has exposed our country's lack for COVID testing kits and proper funding by the government is required especially appropriate provisions be provided for supporting the below poverty populations. COVID has hard hit the poorer classes and hence measures should be taken for their survival for future as well.Hence, India should have a stringent action plan and proper management for when a pandemic strikes-a plan that is creative, disciplined and above all sensitive keeping in mind for all classes. (Triggle et al., 2020) This would involve significant funding in healthcare research and development. (Gaidhane et al., 2020, Jachak et al., 2020, Joseph et al., 2020, Rudhrabatla et al., 2019, Khatib et al., 2020 and Thomas et al., 2021) A number of reported studies in this region were reviewed. Some interesting studies on Covid-19 in healthcare were reported by (Phansopkar et.al.2020, Patel et.al.2020, Pate et.al.,2020, Pasari et.al.2020 and Nubudey et.al.2020).

\section{CONCLUSION}

In conclusion, we need to see the new changes that is to be bought and inculcating those changes for good can help us cope with the pandemic. We've always complained about time and now when we are having the time we are still complaining. Steps like social distancing and wearing cloth face coverings may feel like an inconvenience, but it's the best way right now to protect our family, friends, and neighbours who may be vulnerable.

The government has set out its plan to return life to as near normal as we can, for as many people as we can, as quickly and as possible to safeguard livelihoods, but in a way that continues to protect our communities and our healthcare community. The most important thing we can continue to do is to stay alert, control the virus, and, in doing so, save lives. We need to understand the essence of time and try to set our goals keeping it in mind. Focus on the important and slowing down whenever we get carried away is the key. We all need to help one another be it from any part of society and stand united against this pandemic we're facing.

\section{REFERENCES}

Chang, Y.K., Hung, C.L., Timme, S., Nosrat, S. and Chu, C.H., 2020. Exercise Behavior and Mood during the COVID-19 Pandemic in Taiwan: Lessons for the Future. International journal of environmental research and public health, 17(19), p.7092.

DePierro, J., Lowe, S. and Katz, C., 2020. Lessons learned from 9/11: Mental health perspectives on the COVID-19 pandemic. Psychiatry research, 288, p.113024.

Forman, R., Atun, R., McKee, M. and Mossialos, E., 2020. 12 Lessons learned from the management of the coronavirus pandemic. Health Policy.

Gaidhane, S., Khatib, N., Zahiruddin, Q.S., Gaidhane, A., Telrandhe, S. and Godhiwal, P., 2020. Depression, anxiety and stress among the general population in the time of COVID-19 lockdown: A cross-sectional study protocol. International Journal of Research in Pharmaceutical Sciences, 11(Special Issue 1).

Gudi, S.K. and Tiwari, K.K., 2020. Preparedness and lessons learned from the novel coronavirus disease. The international journal of occupational and environmental medicine, 11(2), p.108.

Jachak, S., Phansopkar, P. and Naqvi, M.W., 2020. Impact of covid-19 in India, a disastrous pandemic outbreak. International Journal of Research in Pharmaceutical Sciences, 11(Special Issue 1).

Joseph, M.B., Pohekar, S., Raut, A. and Patil, M., 2020. The palliative care and covid-19 pandemic. International Journal of Research in Pharmaceutical Sciences, 11(Special Issue 1).

Kaebnick, G.E. and Haupt, L., 2020. Learning from a Pandemic. Hastings Center Report, 50(3), pp.3-3.

Kalfa, D., 2020. Commentary: Lessons learned during the coronavirus disease 2019 pandemic could make us better at something. JTCVS Techniques, 3, pp.267-268.

Khan, T., Agnihotri, K., Tripathi, A., Mukherjee, S., 
Agnihotri, N. and Gupta, G., 2020. COVID-19: a worldwide, zoonotic, pandemic outbreak. Altern. Ther. Health Med, 26, pp.56-64.

Khanna, R.C., Cicinelli, M.V., Gilbert, S.S., Honavar, S.G. and Murthy, G.V., 2020. COVID-19 pandemic: Lessons learned and future directions. Indian Journal of Ophthalmology, 68(5), p.703.

Khatib, M.N., Gaidhane, S., Khatib, M., Ahmed, M., Gaidhane, A. and Syed, Z.Q., 2020. SARS-CoV and SARS-CoV-2: Similar viruses with different trajectories. Wutan Huatan Jisuan Jishu, 16(5).

Khoo, E.J. and Lantos, J.D., 2020. Lessons learned from the COVID-19 pandemic. Acta Paediatrica, 109(7), pp.1323-1325.

Latchoumi, T.P., Ezhilarasi, T.P. and Balamurugan, K., 2019. Bio-inspired weighed quantum particle swarm optimization and smooth support vector machine ensembles for identification of abnormalities in medical data. SN Applied Sciences, 1(10), pp.1-10.

Lawrence, K., Hanley, K., Adams, J., Sartori, D.J., Greene, R. and Zabar, S., 2020. Building telemedicine capacity for trainees during the novel coronavirus outbreak: a case study and lessons learned. Journal of general internal medicine, 35(9), pp.2675-2679.

Miller, E.L., 2020. Dealing with uncertainty: Lessons learned from COVID-19. Pain Management Nursing, 21(4), pp.305-306.

Nibudey, A.R., Baliga, V.S. and Dhadse, P.V., 2020. To Keep COVID-19 Out of Hospitals in India--Are We Prepared?. Journal of Evolution of Medical and Dental Sciences, 9(37), pp.2751-2755.

Pasari, A.S., Bhawane, A., Balwani, M.R., Tolani, P., Ramteke, V. and Deshpande, N., 2020. Knowledge about COVID-19 and Practices among Hemodialysis Technicians in the COVID-19 Pandemic Era. International journal of nephrology, 2020.

Pate, B.S., Yeola, M.E., Gawande, A., Singh, A.K. and Tayade, H.A., 2020. Best Practices for Endoscopic Procedures in Covid-19 Pandemic. Journal of Evolution of Medical and Dental Sciences, 9(49), pp.3760-3767. Patel, M.P., Kute, V.B., Goswami, J. and Balwani, M.R., 2020. Hospitals may Become "Disease Hotspots" for COVID-19 amid Shortage of Personal Protective Equipment. Indian journal of critical care medicine: peer-reviewed, official publication of Indian Society of Critical Care Medicine, 24(11), p.1145.

Phansopkar, P.A., Naqvi, W.M. and Sahu, A.I., 2020. COVID-19 Pandemic-A Curse to the Physical Well-Being of Every Individual in Lock-Down. Journal of Evolution of Medical and Dental Sciences, 9(35), pp.2561-2567. Roman, J., 2020. The Coronavirus Pandemic-Lessons Learned?. The American Journal of the Medical Sciences, 360(3), p.313.

Rudhrabatla, V.S.A., Sudhakar, B. and Reddy, K.V.N., 2019. Ritonavir loaded surface modified stealth solid lipid nanoparticles: full factorial

Sterpetti, A.V., 2020. Lessons learned during the COVID19 virus pandemic. Journal of the American College of Surgeons, 230(6), pp.1092-1093.

Thomas, B. and Chackole, D.S., 2021. Economic Impacts Of Covid 19. European Journal of Molecular \& Clinical Medicine, 7(7), pp.5812-5819.

Triggle, C.R., Bansal, D., Abd Farag, E.A.B., Ding, H. and Sultan, A.A., 2020. COVID-19: learning from lessons to guide treatment and prevention interventions. MSphere, 5(3). 